\title{
Inclusão de alunos surdocegos e a atuação de professores no ensino comum: revisão sistemática
}

\author{
Ana Paula Silva Cantarelli Branco* \\ Daniela Leal ${ }^{* *}$
}

\section{Resumo}

Esta pesquisa tem por objetivo apresentar uma revisão sistemática de estudos sobre a inclusão dos alunos surdocegos e a atuação dos professores e equipe de profissionais, no âmbito escolar. Optou-se por pesquisas com o formato de artigos, dissertaçóes e teses. Utilizou-se da base de dados do Portal de Periódicos da Coordenação de Aperfeiçoamento de Pessoal de Nível Superior, para os periódicos online, e o Portal Digital de Teses e Dissertaçóes. Selecionaram-se publicações dos últimos vinte anos, ou seja, de 1996 a 2016. Combinaram-se aos critérios anteriores, os descritores: Surdocegueira, Educação Especial, Deficiência, Aprendizagem, Inclusão, Escola, Professor, Ensino, Docência e Estratégias de Ensino e seus termos correlatos na língua inglesa. Após a seleção, por meio da leitura do título e resumo, encontraram-se 28 artigos em que 03 foram analisados. A busca pelas teses e dissertaçóes resultaram em 11 pesquisas e 06 foram analisadas por estarem relacionadas ao objeto do estudo. A revisão possibilitou a análise de pesquisas no âmbito nacional, no geral, e 01 internacional. Foram analisados os objetivos, amostras, tipos de estudo, instrumento e ênfase nos principais resultados. Os estudos implicaram em ausência de açóes planejadas e fragmentação das atividades do Atendimento Educacional Especializado, bem como falta de formação de profissionais professores e guias-intérpretes especializados na prática pedagógica ao aluno surdocego. Conclui-se que se faz necessário criar possibilidades para promoção de formação continuada em serviços a fim de oportunizarem aos professores de salas de recursos, professor de sala comum e guias-intérpretes açóes articuladas entre suas práticas cotidianas.

Palavras-chave: Educação Especial; Inclusão; Surdocego.

\footnotetext{
* Doutoranda em Educação Especial pela Universidade Federal de São Carlos - UFSCar, São Carlos, São Paulo, Brasil.

** Doutora e Mestre em Psicologia da Educação pela PUC-SP, São Paulo, São Paulo, Brasil.
} 


\section{Inclusion of deafblind students and the regular teachers performance: a systematic bibliographic review}

\section{Abstract}

This research aims to present a systematic review of studies on the inclusion of deafblind students and the performance of teachers and staff in the school context. We research articles, dissertations and theses. For online journals we went to the website of CAPES (Coordenação de Aperfeiçoamento de Pessoal de Nível Superior, in portuguese), and also we used the website "Portal Digital de Teses e Dissertaçóes". Twenty years of publications were selected, from 1996 to 2016. The following criteria were combined: Deafblindness, Special Education, Disability, Learning, Inclusion, School, Teacher, Teaching, Teaching and Teaching Strategies, in both Portuguese and English language. After the selection, through the reading of the title and abstract, we found 28 articles in which 03 were analyzed. The search for the theses and dissertations resulted in 11 researches and 06 were analyzed because they were related to the object of the study. The review enabled the majority analysis of research at the national level, and one in the international context. The objectives, samples, types of study, instrument and emphasis on the main results were analyzed. The studies implied in the absence of planned actions and fragmentation of the activities of the Specialized Educational Assistance, as well as lack of training of professional teachers and interpreter guides specialized in the pedagogical practice to the deafblind student. It is concluded that it is necessary to create possibilities for the promotion of continuous training in services in order to provide opportunities articulated in their daily practices to teachers of resource rooms, teacher of common room and guides-interpreters.

Keywords: Special Education; Inclusion; deafblind.

\section{Introdução}

A surdocegueira é definida, conforme documentos legais sobre Estratégias e Orientaçôes Pedagógicas (BRASIL, 1993; 1998; 2001; 2004), como uma perda substancial total ou parcial da visão e da audição, acarretando comprometimento "[...] de habilidades educacionais, vocacionais, de lazer e sociais" (BRASIL, 2004, p. 10).

Minnes e Treffy $(1991 ; 1999)$ acrescentam que a surdocegueira deve ser compreendida não como a incapacidade em enxergar nem mesmo como a incapacidade de ouvir, pois não deve ser levado em consideração as disfunçôes da comunicação e percepção, embora ambas estarem comprometidas.

Ceder-Nascimento (2005; 2010), Masini (2002) e Santos, Galvão e Araújo (2009), apesar do comprometimento em duas das vias sensoriais, a surdocegueira não é mais compreendida como uma deficiência múltipla; pois, a surdez conjuntamente com cegueira denotam uma especificidade da deficiência, não a soma do comprome- 
timento visual e auditivo; é uma condição singular que pressupóe um atendimento diferenciado do que é ofertado à pessoa que tenha apenas um dos tipos de comprometimento sensorial: surdez ou cegueira.

Assim como a inclusão escolar dos demais alunos que compõem o público-alvo da educação especial, os surdocegos têm direito garantido à educação, uma vez que se trata de especificidade da educação especial. Isto porque, além do processo de inclusão escolar ser um dos principais meios para se alcançar à Educação Especial, os dispositivos legais (documentos e legislaçóes) de nosso país, como a Constituiçấo da República Federativa do Brasil de 1988 (BRASIL, 1988), a Lei de Diretrizes e Bases da Educação Nacional (LDBEN), de 1996 (BRASIL, 1996), a Resolução CNE/CEB N. ${ }^{\circ}$ 02/2001 (BRASIL, 2001a), a Resolução CNE/CEB N. . 04/2009 (BRASIL, 2009) e a Resolução CNE/CEB N.o 04/2010 (BRASIL, 2010), afirmam o direito e a permanência destes nos espaços regulares de ensino.

A Constituição Federal de 1988, por exemplo, dispõe da obrigatoriedade de matrícula no ensino fundamental nos estabelecimentos de ensino público ou privado dos alunos com deficiência; mais precisamente, em seu artigo 208, inciso III, afirma ser dever do Estado a garantia do "atendimento educacional especializado" aos portadores de deficiência, preferencialmente na rede regular de ensino (BRASIL, 1988).

Por conseguinte, a LDBEN (1996) preconizou em seus artigos 58, 59 e 60 que a Educação Especial, como modalidade de educação escolar, deve ser oferecida preferencialmente na rede regular de ensino para alunos portadores de necessidades especiais.

Desse modo, para que os alunos sejam incluídos e tenham êxito acadêmico, os professores do ensino comum regular e professores especializados necessitam estarem capacitados a fim de oferecer o ensino de qualidade a esses alunos.

A Resolução CNE/CEB no 02 de 2001a, no inciso IV, do artigo 8º, traz que as escolas de rede regular de ensino devem propiciar, na organização de suas classes comuns:

[...] serviços de apoio pedagógico especializado, realizado, nas classes comuns, mediante: a) atuaçáo colaborativa de professor especializado em educação especial; b) atuação de professores-intérpretes das linguagens e códigos aplicáveis; c) atuação de professores e outros profissionais itinerantes intra e interinstitucionalmente; d) disponibilização de outros apoios necessários à aprendizagem, à locomoção e à comunicação (BRASIL, 2001a, p. 02).

As normas da resolução mencionam que os professores necessitam trabalhar em colaboração com vistas a atingir o objetivo proposto pelo Atendimento Educacional Especializado e, para tanto, a Resoluçáo CNE/CEB N.o 04 de 2009, complementa em seu art. 12., que: "Para atuação no AEE o professor deve ter formação inicial que o habilite para o exercício da docência e formação específica para a Educação Especial" (BRASIL, 2009, p. 03). 
Nesse sentido, pode-se afirmar que, os documentos aqui reunidos somam esforços para que o público-alvo da educação especial tenham seus direitos garantidos [...] serviços de apoio pedagógico especializado, realizado, nas classes comuns, mediante: a) atuação colaborativa de professor especializado em educação especial; b) atuação de professores-intérpretes das linguagens e códigos aplicáveis; c) atuação de professores e outros profissionais itinerantes intra e interinstitucionalmente; d) disponibilização de outros apoios necessários à aprendizagem, à locomoção e à comunicação (BRASIL, 2001a, p. 02).

A Resolução CNE/CEB N. 04 de 2010, aponta em seu artigo 9º que, "A escola de qualidade social adota como centralidade o estudante e a aprendizagem" (BRASIL, 2010, p.03) e, nesse sentido, para concretização deste artigo, o mesmo destaca em seus incisos de III a V, o que se faz necessário:

III - foco no projeto político-pedagógico, no gosto pela aprendizagem e na avaliaçáo das aprendizagens como instrumento de contínua progressáo dos estudantes; IV - inter-relação entre organização do currículo, do trabalho pedagógico e da jornada de trabalho do professor, tendo como objetivo a aprendizagem do estudante; V - preparaçáo dos profissionais da educação, gestores, professores, especialistas, técnicos, monitores e outros [...] (BRASIL 2010, p. 03).

Com vistas a proporcionar uma aprendizagem voltada aos princípios de ascensão contínua dos estudantes deve-se valorizar cada etapa de seu processo de aprendizagem, conectando-as à organização do currículo, que deve ser integrado ao trabalho pedagógico do professor, visando a coparticipaçáo de outros atores a fim de valorizar a diferença do aluno público-alvo da educação especial.

Diante das normativas apresentadas e dos teóricos anteriormente citados, principalmente ao afirmarem sobre a importância de um atendimento diferenciado ao público-alvo da educação especial, neste artigo será dado ênfase, em especial, à inclusão escolar do aluno surdocego. Para tanto, seu objetivo foi uma revisão sistemática de estudos sobre a inclusão dos alunos surdocegos e a atuação dos professores e equipe de profissionais, no âmbito escolar.

\section{Percurso metodológico}

Efetuou-se revisão sistemática adotada por Galvão, Sawada e Trevizan (2004, p. 550) como "[...] recurso importante da prática baseada em evidências, onde os resultados de pesquisas são coletados, categorizados, avaliados e sintetizados". Para cumprir com tal forma de sistematização e de análise, foi utilizado o "Protocolo de análise", elaborado pelas autoras, que permite uma análise baseada em sete fases.

A primeira fase refere-se especificamente à construção do protocolo, ou seja, os artefatos que definem a pergunta da revisão, os critérios de inclusão, as estratégias para as buscas nas pesquisas, a coleta, bem como a síntese dos dados. No caso desta pesquisa, os artefatos foram os estudos que versaram sobre os meios com que os pro- 
fessores do ensino comum, professores de salas de recursos especiais e guia-intérpretes adotam como estratégias em sala de aula para um melhor aprendizado dos alunos surdocegos.

$\mathrm{Na}$ segunda fase, mais conhecida como definição da pergunta, para garantir a solidez, formulou-se a pergunta que guiou a revisão, bem como os estudos que foram incluídos, quais as estratégias adotadas no momento da seleção, identificação, dentre dados que fizeram parte do escopo e, que, portanto, se fizeram relevante na coleta dos dados.

A pergunta norteadora desta pesquisa foi: "Como os estudos selecionados abordaram a inclusão no ensino comum de alunos surdocegos e quais meios adotados pelos professores para haver o ensino e a aprendizagem?". Esta indagaçáo constitui-se num dado muito importante, porque propiciou a direção para a execuçáo de outras açóes associadas ao processo, como: a definiçáo dos participantes e dos meios para as açóes a serem analisadas, bem como o modo com que os resultados foram interpretados.

A terceira fase, nomeada como busca dos estudos e indispensável à pesquisa, visa a procura de estudos na literatura para a condução da revisão sistemática, utilizando-se de uma estratégia ampla, a fim de incluir o máximo de materiais disponíveis. Neste caso, a busca pelos estudos ocorreu, inicialmente, no Portal de Periódicos da Coordenação de Aperfeiçoamento de Pessoal de Nível Superior (CAPES), cujo acervo reúne mais de 37 mil títulos, com texto completo, em 126 bases referenciais; conta ainda com 11 bases voltadas para patentes e um rol de diversos livros, enciclopédias, obras específicas, normas técnicas, estatísticas e conteúdo audiovisual.

Optou-se por essa base de dados por congregar uma coleção significativa de indexadores como o SciELO, Scopus, Web of Science, dentre outros. Mas, num segundo momento, buscou-se na Biblioteca Digital de Teses e Dissertaçóes (BDTD), que reúne cerca de 468.393 documentos, dentre esses, 125.936 teses e 342.457 dissertaçóes, outras referências que respondessem à pergunta anteriormente elaborada.

A quarta fase, denominada de seleção dos estudos, consiste em buscar por todas pesquisas que congregaram os descritores a seguir: Surdocegueira, Educação Especial, Deficiência, Aprendizagem, Inclusão, Escola, Professor, Ensino, Docência e Estratégias de Ensino, Deafblindness, Special Education, Deficiency, Learning, Inclusion, School, Teacher Teaching, Teaching strategies.

Como critério de inclusão elencou-se: (a) periódicos revisados por pares e dissertaçóes e teses (b) publicados entre 1996 e 2016; (c) estudo de campo que retratou sobre a escolarização do aluno surdocego; (d) tenham sido publicados em língua portuguesa, inglesa ou espanhola.

Excluiu-se da amostra estudos que não estavam disponibilizados na íntegra. Mas também, os que se reportaram para as causas da surdocegueira, e por fim, àqueles que discutiam apenas a inserção social do surdocego. 
O período de busca pelos materiais ocorreu entre os meses de Setembro e Outubro de 2016, sendo a cronologia adotada para o recorte, os últimos vinte anos.

A quinta fase, avaliação crítica dos estudos, permitiu a análise de delineamentos, possibilitou avaliação do rigor metodológico, com o intuito de averiguar os métodos e resultados dos estudos encontrados. Nesse sentido, foram analisados os locais de coletas, anos de publicações, amostras, tipos de estudos e instrumentos e principais resultados. Ressalta-se que, nesta fase, foram excluídos estudos que não se relacionavam com tema proposto como, por exemplo, um estudo encontrado a partir dos descritores que focava nos aspectos biopsicossociais do surdocego, sem apresentar nenhuma inferência ao processo de escolarizaçáo.

Na sexta fase, ou melhor, na coleta de dados das teses e dissertaçóes foram coletados por meio do auxílio do instrumento desenvolvido por Mendes, Ferreira e Nunes (2002), que garantiu que os critérios descritos acima fossem acoplados, relacionando-os com a pergunta que norteou o trajeto dos estudos.

No fluxograma (figura 1), a seguir, seguem as possíveis combinaçôes realizadas com base nas etapas anteriormente descritas.

Figura 1 - Fluxograma dos descritores da revisão sistemática

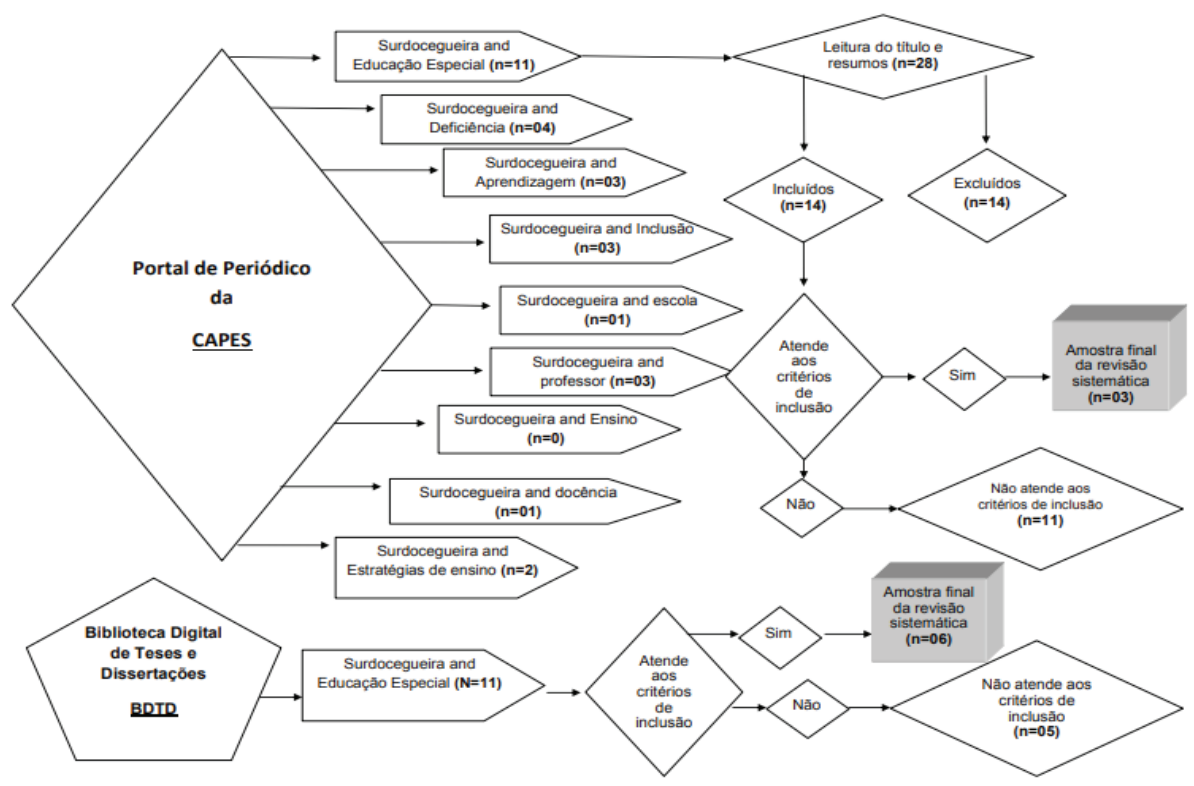

Fonte: Elaboração própria.

A sétima fase, denominada de síntese dos dados, refere-se às consideraçóes resultantes de cada estudo, e tem como critério fornecer estimativa da eficácia da intervenção investigada. Os dados encontrados forneceram estimativa de solidez em relaçáo a investigação o que permitiu uma investigaçáo descritiva das amostras, tipos 
de estudos, instrumentos e ênfase nos principais resultados, que serão apresentados e analisados descritivamente a seguir, por intermédio de uma revisão sistemática qualitativa (GALVÃO; SAWADA; TREVIZAN, 2004).

\section{Resultados e discussões}

Os resultados culminaram em dados obtidos no Portal de Periódicos da CAPES em que se enveredaram para os aspectos da surdocegueira e as relaçôes escolares totalizando-se em apenas (02) artigos sendo um de 2013 e um de 2014, publicados respectivamente, pelas Revista de Educaçáo Especial da Universidade Federal de Santa Maria (UFSM) e pela Revista Brasileira de Educação Especial (RBEE) e (01) livro, em formato PDF , publicado no ano de 2009, pela Editora da Universidade Federal da Bahia (UFBA).

Os dados identificados no quadro 1 , referem-se as pesquisas realizadas no portal da Biblioteca Digital de Teses e Dissertaçóes (BDTD), indicando (03) Teses e (03) dissertaçóes conforme descrito a seguir.

Quadro 1- Fontes da Biblioteca Digital Brasileira de Teses e Dissertaçóes

\begin{tabular}{|c|c|c|c|}
\hline Sigla & Tipo & Universidade & Ano \\
\hline 1BDTD & Tese & UFBA $^{2}$ & 2015 \\
\hline 2BDTD & Dissertação & UFBA & 2015 \\
\hline 3BDTD & Dissertação & UEL $^{3}$ & 2015 \\
\hline 4BDTD & Tese & PUC $^{4}$ & 2014 \\
\hline 5BDTD & Dissertação & UFSCar $^{5}$ & 2013 \\
\hline 6BDTD & Tese & UFSCar & 2003 \\
\hline
\end{tabular}

Fonte: Elaboraçáo própria.

Diante do exposto, os artigos, por exemplo, foram identificados pelas siglas $1 \mathrm{PC}$ (pesquisa voltada ao aluno surdocego), 2PC (pesquisa voltada aos professores do atendimento educacional especializado) e 1PCL (pesquisa voltada à caracterizaçáo da cegueira e da surdocegueira). Já, com relação às dissertaçôes e teses, suas siglas, como já apresentadas no quadro anterior, foram: 1BDTD (pesquisa voltada à atuação do guia-intérprete); 2BDTD (pesquisa voltada à percepção sobre a inclusão pelo aluno com surdocegueira); 3BDTD (pesquisa voltado ao professor especializado, ao aluno surdocego e ao professor de sala comum; 4BDTD (pesquisa voltada à atuação de uma professora de uma criança com surdocegueira e uma criança com deficiência múltipla); 5BDTD (pesquisa voltada à inclusão de um pré-adolescente com surdocegueira); e, finalmente, a 6BDTD (pesquisa voltada aos aspectos de atuaçáo de professores do atendimento educacional especializado e professor de sala comum). Um breve panorama desses estudos, será observado, a seguir, nos Quadros 2 e 3, com intuito de apresentar os sujeitos envolvidos, o tipo de estudo e de instrumento de coleta e principais resultados, analisados com base no objetivo e no propósito do estudo deste artigo. 
Quadro 2 - Caracterizaçáo dos dados dos estudos analisados no Portal de Periódicos da CAPES

\begin{tabular}{|c|c|c|c|c|}
\hline Sigla & Amostra & Tipo de estudo & Instrumento & $\begin{array}{c}\text { P r i n c i p a i s } \\
\text { resultados }\end{array}$ \\
\hline $1 \mathrm{PC}$ & $\begin{array}{l}\text { (04) alunos } \\
\text { surdocego, } \\
\text { sendo três } \\
\text { do Ensino } \\
\text { Fundamental } \\
\text { II e um do } \\
\text { Ensino Médio }\end{array}$ & Estudo de caso & Entrevista & $\begin{array}{l}\text { Falta de açóes } \\
\text { planejadas no } \\
\text { que concerne } \\
\text { ao Atendimento } \\
\text { Educacional } \\
\text { Especializado. }\end{array}$ \\
\hline $2 \mathrm{PC}$ & $\begin{array}{l}(10) \\
\text { Professores } \\
\text { de Educaçáo } \\
\text { Especial e (14) } \\
\text { Professores } \\
\text { do Ensino } \\
\text { Comum. }\end{array}$ & - & $\begin{array}{l}\text { Observação } \\
\text { (participante) } \\
\text { e inquérito } \\
\text { por meio de } \\
\text { questionário }\end{array}$ & $\begin{array}{l}\text { Eficácia da } \\
\text { Unidade de Apoio } \\
\text { Especializado } \\
\text { para a Educação } \\
\text { de Alunos com } \\
\text { Multideficiências. }\end{array}$ \\
\hline 1PCL & $\begin{array}{l}\text { Livro e autores } \\
\text { de referência } \\
\text { da área. }\end{array}$ & $\begin{array}{l}\text { Revisão de } \\
\text { literatura }\end{array}$ & Não se aplica & $\begin{array}{l}\text { Qualidade na } \\
\text { prática pedagógica } \\
\text { lançando mão de } \\
\text { técnicas eficazes } \\
\text { no conjunto de } \\
\text { atividades }\end{array}$ \\
\hline
\end{tabular}

Quadro 3 -Caracterizaçâo dos dados dos estudos analisados na base de dados da Biblioteca Digital de Teses e Dissertaçōes

\begin{tabular}{|c|l|l|l|l|}
\hline Sigla & \multicolumn{1}{|c|}{ Amostra } & Tipo de estudo & Instrumento & $\begin{array}{l}\text { P r i n c i p a i s } \\
\text { resultados }\end{array}$ \\
\hline 1BDTD & $\begin{array}{l}\text { (11) Guia- } \\
\text { intérpretes. }\end{array}$ & Exploratório & $\begin{array}{l}\text { Entrevista } \\
\text { semiestrutura } \\
\text { e observação } \\
\text { direta. }\end{array}$ & $\begin{array}{l}\text { Escolarização } \\
\text { e formação } \\
\text { profissional } \\
\text { insuficientes }\end{array}$ \\
\hline 2BDTD & $\begin{array}{l}\text { (02) alunos } \\
\text { surdocegos }\end{array}$ & História de vida & $\begin{array}{l}\text { Entrevista } \\
\text { narrativa }\end{array}$ & $\begin{array}{l}\text { Aprendizagens } \\
\text { parciais com } \\
\text { a libras, a } \\
\text { comunicação } \\
\text { oral e o sistema } \\
\text { de leitura e } \\
\text { escrita braille }\end{array}$ \\
\hline 3BDTD & $\begin{array}{l}\text { (01) professora } \\
\text { do Ensino } \\
\text { comum e (02) } \\
\text { especialistas }\end{array}$ & Colaborativo & $\begin{array}{l}\text { Entrevista, } \\
\text { observaçáo } \\
\text { assistemática } \\
\text { e análise } \\
\text { documental }\end{array}$ & $\begin{array}{l}\text { Adaptaçóes } \\
\text { e elaboração } \\
\text { de recursos } \\
\text { pedagógicos }\end{array}$ \\
\hline
\end{tabular}




\begin{tabular}{|l|l|l|l|l|}
\hline 4BDTD & $\begin{array}{l}\text { (01) professora } \\
\text { especializada } \\
\text { e (02) alunos, } \\
(01) \text { surdocego } \\
\text { e com (01) } \\
\text { com deficiência } \\
\text { múltipla. }\end{array}$ & Estudo de caso & $\begin{array}{l}\text { Observação } \\
\text { participante e } \\
\text { entrevista semi- } \\
\text { estruturada }\end{array}$ & $\begin{array}{l}\text { Atividades de } \\
\text { comunicaçáo } \\
\text { alternativa } \\
\text { visando a } \\
\text { comunicaçáo } \\
\text { não verbal. }\end{array}$ \\
\hline 5 BDTD & $\begin{array}{l}\text { (01) Pré- } \\
\text { adolescente } \\
\text { surdocego. }\end{array}$ & Estudo de caso & $\begin{array}{l}\text { Entrevista e } \\
\text { observaçóes }\end{array}$ & $\begin{array}{l}\text { Falta de } \\
\text { recursos ópticos } \\
\text { e náo ópticos } \\
\text { pela Instituição. }\end{array}$ \\
\hline 6BDTD & $\begin{array}{l}\text { (02) alunas } \\
\text { surdocegas e } \\
\text { suas famílias e } \\
(01) \text { professora } \\
\text { do ensino } \\
\text { comum. }\end{array}$ & Estudo de caso & $\begin{array}{l}\text { Entrevista } \\
\text { semiestruturada }\end{array}$ & $\begin{array}{l}\text { Uso simultâneo } \\
\text { de vários } \\
\text { recursos de } \\
\text { comunicação }\end{array}$ \\
\hline
\end{tabular}

Fonte: Elaboração própria.

No artigo 1PC e na tese 1BDTD, por intermédio de estudo de caso e de uma pesquisa exploratória, respectivamente, identificou-se que a atuação tanto dos professores de sala comum quanto dos professores do Atendimento Educacional Especializado (AEE), denotam ausência de ação planejada e informações adequadas; o que acaba por gerar contextos de fragmentaçấo das atividades, isolamento dos profissionais, ações pedagógicas desarticuladas, desconhecimento das necessidades educacionais especiais dos alunos com surdocegueira, consequente sua invisibilidade no espaço escolar, bem como a falta e/ou precária formaçăo de professores especializados (GALVÃO; MIRANDA, 2013; ALMEIDA, 2015).

No artigo 1PCL, as autoras verificaram que as escolas necessitam melhorar sua prática pedagógica, utilizando-se de técnicas eficazes no trabalho com o aluno surdocego a fim de garantir que sua vida escolar seja compartilhada desde a mais tenra idade, aprendendo coletivamente, no âmbito da escola comum, em busca de alto funcionamento acadêmico a fim de possibilitar uma vida de aprendizagem satisfatória com apoio necessário (SANTOS, GALVÃO; ARAÚJO, 2009).

Visando a prática pedagógica do professor, consequentemente o aprendizado dos alunos surdocegos nos espaços escolares, a Lei de Diretrizes e Bases da Educaçáo Nacional (LDB) N.o 9.394, de 1996, no capítulo V, Da Educação Especial, artigo 59, capítulo III, preconiza a necessidade de especialização adequada em nível médio ou superior que capacite/prepare o professor ao atendimento dos alunos nas classes comuns de ensino (BRASIL, 1996). Possibilitando, assim, ao professor "aprofundar o caráter interativo e interdisciplinar da atuação nas salas comuns do ensino regular [e] nas salas de recursos", bem como "contemplar conhecimentos de gestão de sistema 
educacional inclusivo, tendo em vista o desenvolvimento de projetos em parceria com outras áreas, visando à acessibilidade arquitetônica, os atendimentos de saúde, a promoção de açóes de assistência social, o trabalho e justiça”" (BRASIL, 2008, p. 11).

$\mathrm{O}$ artigo $2 \mathrm{PC}$, assinalou que professores do ensino comum regular e professores da escola especializada verificaram que as Unidades de Apoio Especiali $\neg$ zado para a educação de Alunos com Multideficiência e Surdocegueira Congênita (UAEM) foram as melhores respostas educativa para alunos com multideficiência, tanto para a realização de aprendizagens, quanto para de fins socialização (BARROSO; MESQUISTA, 2014).

Um dado relevante voltou-se para as falas dos professores de educação especial que disseram sentirem-se mais preparados para trabalhar com este público quando comparados com as respostas dos professores de ensino comum regular. E as opinióes sobre a preparação para o atendimento aos alunos do público-alvo da educação especial quando perguntado para o professor do ensino comum, revelaram que os professores especialistas apresentam técnicas diferenciadas e, portanto, encontram-se melhores capacitados.

De acordo com a Resolução no 02, Diretrizes Nacionais para a Educação Especial na Educação Básica, de 11 de setembro de 2001, estabeleceu que para o atendimento aos alunos com necessidades educacionais especiais, tanto os professores do Ensino Comum Regular, quanto os de Ensino Especial devem participar de açóes conjuntas e especializarem-se com vistas a ir ao encontro das necessidades de seus alunos. Nesse sentido, os professores precisam estar:

[...] capacitados para atuar em classes comuns com alunos que apresentam necessidades educacionais especiais [...] I - perceber as necessidades educacionais especiais dos alunos e valorizar a educação inclusiva, [...] II - flexibilizar a ação pedagógica nas diferentes áreas de conhecimento de modo adequado às necessidades especiais de aprendizagem, [...] IV - atuar em equipe, inclusive com professores especializados em educação especial (BRASIL, 2001a).

Com fins de corroborar com os achados acima, Costa (2015, p. 414) propóe que os professores necessitam desenvolverem-se com uma postura crítica, rompendo com ideias reducionistas de:

[...] formação que prepara e/ou instrumentaliza, desvinculada da autonomia teórica, crítica e reflexiva, da autoria docente e do potencial da educação solidária no processo de emancipação e humanização de alunos e professores na escola. Escola na qual a alienação da formação teórica seja enfrentada e problematizada pela educação em suas dimensões política, social, histórica e humana.

A Resoluçáo no 4, de 2009, institui as Diretrizes Operacionais para o Atendimento Educacional Especializado na Educação Básica, modalidade Educaçáo Especial, em que indica em seu artigo 12 que o professor para atuar no AEE necessita ter formação inicial que o habilite ao exercício da docência e formação específica para a Educação Especial sendo que, segundo o artigo 13, incisos de II a VII, suas atribuiçôes devem estar voltadas à: 
II - elaborar e executar o Plano de Atendimento Educacional Especializado, avaliando a funcionalidade e a aplicabilidade dos recursos pedagógicos e de acessibilidade; IV - acompanhar a funcionalidade e a aplicabilidade dos recursos pedagógicos e de acessibilidade na sala de aula comum do ensino regular, bem como em outros ambientes da escola; VII - estabelecer articulaçáo com os professores da sala de aula comum, visando à disponibilização dos serviços, dos recursos pedagógicos e de acessibilidade e das estratégias que promovem a participaçáo dos alunos nas atividades escolares (BRASIL, 2009).

Assim, cabe a todo professor desenvolver o Plano de Atendimento Educacional Especializado com vistas a proporcionar os recursos pedagógicos tanto em ambientes de sala de aula, quanto no contexto total da escola.

A dissertação 5 BDTD deu importância na adaptação de recursos visuais acessíveis com a intenção de serem utilizados adequadamente. Entretanto, segundo a mesma, ao longo de sua pesquisa, ela chega à conclusão de que não existe um apoio de recursos ópticos (óculos, lupa, caneta de ponta porosa, cadernos com linhas reforçadas, lápis com grafite escuro) e não ópticos (ambientais - aproximação da lousa e da janela para maior iluminação) pela Instituição diante dessa nova realidade. Nesse sentido, o estudo possibilitou reflexóes acerca de assegurar que haja a presença do aluno com Síndrome de Usher, na sala de aula, para que o seu direito constitucional seja exercido (CAMBRUZZI, 2013).

A dissertação 2 BDTD investigou alunos com surdocegueira que narraram sobre diversas formas de comunicação aprendidas, porém, de modo parcial, para o processo de inclusão escolar com a libras, a comunicação oral e o sistema de leitura e escrita Braille, pois quanto ao atendimento educacional especializado, não foram atendidas as suas reais necessidades (FARIAS, 2015).

A Tese 4BDTD deu ênfase na comunicação da professora com alunos com surdocegueira e verificou que as interaçóes foram verbais, toque (contato e vibraçáo), visual, auditiva (ritmo) e sinais de libras. No estudo um, os comportamentos de atenção de S1 se mantinha, já S2 focava atenção ao objeto em atividades que envolviam música e ritmo. Em relação as formas de comunicação não verbal S1 apresentou vocalização, toque, contato corporal; S2, olhar, movimentos corporais e vocalização. No estudo dois, a professora sentiu-se satisfeita pelo seu trabalho ao observar o desenvolvimento de seus alunos, pois respeitou as características individuais para o uso de estratégias de atendimento. Mas, por outro lado, referiu-se a alguns momentos não ter se comunicado, além de não oferecer o tempo de resposta necessária aos alunos (VILLAS-BOAS, 2014).

Revelando, assim que, os professores devem promover outros modos de comunicação.

A este respeito, a Lei Brasileira de Inclusão (LBI) ou Lei N. ${ }^{\circ}$ 13.146, de 6 de julho de 2015, no inciso $\mathrm{V}$, do artigo $3^{\circ}$, deixa claro que a:

$\mathrm{V}$ - [...] forma de interação dos cidadãos que abrange, entre outras opçôes, as línguas, inclusive a Língua Brasileira de Sinais (Libras), a visualizaçáo de textos, o Braille, o sistema de sinalização ou de 
comunicação tátil, os caracteres ampliados, os dispositivos multimídia, assim como a linguagem simples, escrita e oral, os sistemas auditivos e os meios de voz digitalizados e os modos, meios e formatos aumentativos e alternativos de comunicação, incluindo as tecnologias da informação e das comunicaçóes (BRASIL, 2015, p. 02).

Em meio ao arsenal de açóes pedagógicas e que devem estar integradas, não se pode esquecer que o Intérprete de Libras, por exemplo, não tem a função de ensinar, como muitos acabam compreendo; seu papel é o de ser o interlocutor do professor, sobre o conteúdo que ele está explicado. Nesse sentido, Caetano e Lacerda (2014, p. 220) consideram ser fundamental haver parceria entre professor e intérprete, sendo que, "[...] o primeiro tem de dar abertura para que o intérprete possa revelar, além das questôes do aprendiz, suas dúvidas, conhecer os conteúdos ministrados e ter acesso a metodologia eleita pelo professor para a abordagem das temáticas”.

Desse modo, os professores devem estar estritamente ligados com os outros profissionais, com o intuito de auxiliar o aluno a atingir à compreensão necessária para acessar os mesmos conteúdos que estão sendo dirigidos aos colegas de sala de aula.

A dissertação 3BDTD, Godoy (2015) apresentou grandes possibilidades de um trabalho colaborativo na elaboração de mapas e gráficos táteis. As atividades efetuadas em conjunto voltaram-se para ciclos de estudos reflexivos, planejamento das aulas de Geografia, conversas reflexivas e participaçáo da pesquisadora em sala de aula de forma colaborativa junto à aluna com surdocegueira (ASC), à professora de Geografia e à guia-intérprete, visando à utilização dos mapas e gráficos táteis durante as aulas.

Algumas dificuldades se referiram a falta de tempo das professoras especialistas em participarem das atividades referentes à formação docente por meio de ciclos de estudo e reflexôes sobre suas práticas, os horários alternados das docentes e a necessidade de antecipar para ao aluno o material adaptado utilizado em sala de aula e a troca das profissionais especialistas.

Em relação às dificuldades de interlocução entre o professor de sala de recursos do AEE e do professor de sala comum, crê-se que isto ocorra porque o documento que descreve as práticas dos professores que dão apoio aos alunos público-alvo da educação especial, mais conhecido como PNEE/EI (BRASIL, 2008) não especifica de modo categórico o papel do professor do AEE. Isto porque, este profissional, às vezes, tem a função de elaborar atividades diferenciadas daquelas realizadas em sala de aula, de forma complementar ou suplementar de forma que não seja substitutiva à escolarização e, às vezes, têm a função de oferecer recursos, serviços e orientação voltados ao ensino e a aprendizagem nas classes comuns de ensino. Diante dessa indefinição, pode-se dizer, com base em Mendes, Vilaronga e Zerbato (2014), que o trabalho colaborativo entre ambos os profissionais deve envolver açôes em conjunto, bem como, em relação especificamente a prática do $\mathrm{AEE}$, promover "[...] não há nenhuma referência no que diz respeito as atividades em conjunto do professor especializado com o professor de ensino comum para o apoio do processo pedagógico" (MENDES; VILARONGA; ZERBATO, 2014, p. 32). 
E, portanto, embora a pesquisa realizada por Godoy (2015) pautar-se no texto da política, reflete, infelizmente, que as açôes de cada profissional acontecem de modo independente, acarretando ações fragmentadas e desconexas, que prejudicam náo somente a práticas educacionais, mas principalmente a aprendizagem e o desenvolvimento do aluno com surdocegueira.

O estudo 6BDTD avaliou programas de intervenção junto à criança surdocega; o que permitiu verificar o aumento das competências comunicativas a respeito do uso dos sinais, escrita, dactilologia, fala e, gestos. $\mathrm{O}$ autor notou que o desempenho dos alunos, após a implementação de programas de intervenção, contribuiu tanto para com a participação quanto para a concentração e a comunicação nas habilidades voltadas à realização de tarefas. Revelou, também, a importância do processo de formaçáo do professor em serviço, que se mostrou eficaz a medida em que envolveu aspectos teóricos, possibilitando habilidades e oportunidades para o professor observar, praticar e refletir sobre a própria prática de ensino CADER-NASCIMENTO (2003).

\section{Considerações finais}

Primeiramente, considera-se que este estudo possibilitou uma síntese das amostras, dos tipos de estudos, dos instrumentos e da ênfase nos principais resultados encontrados no portal de periódicos da CAPES e Biblioteca Digital Brasileira de Teses e Dissertaçóes - BDTD, nos últimos vinte anos.

Segundo, o resultado de apenas (09) estudos, representam a insuficiência de pesquisas com ênfase no processo de escolarização do aluno público alvo da educação especial, especificamente, dos alunos com surdocegueira. Sendo que, a principal dificuldade ainda está voltada para o planejamento das açóes, bem como diversificaçóes nas estratégias de ensino a esse público.

Terceiro, verificou-se que a falta de açôes planejadas depende de açóes integradas e, portanto, colaborativas entre os professores e profissionais para com o aluno surdocego. Isto porque, devido a complexidade do ensino ao aluno surdocego, percebe que tamanha lacuna na integração e formação continuada dos professores especializados conjuntamente com os professores que não possui tal formação, ainda é um desafio para as políticas que garantem os mesmos, bem como para os dirigentes, gestores escolares oportunizarem tais espaços de formação dentro da própria ação docente nos espaços escolares.

E, por fim, observou-se que embora os estudos sobre a inclusão escolar dos alunos surdocegos ainda se encontrem pouco representativos, mesmo que dentro de possibilidades (materiais, pessoais de formação) os professores de sala comum conjuntamente com os professores de sala de recursos do AEE e os profissionais especializados, como é o caso do guia-intérprete, têm se esforçado para elaborarem e aplicarem estratégias pedagógicas com vistas a promover a acessibilidade desse alunado. Levando a concluirmos que, diante dessa realidade, faz-se necessário um maior fomento em pesquisas que deem visibilidade a esse público, mas, também, a um im- 
prescindível investimento na contrataçóes de mais recursos humanos para contribuir na construção de melhores resultados frente a uma aprendizagem mais satisfatória, uma vez que os professores necessitam refletirem suas práticas e traçar açôes em colaboração.

\section{Referências}

ALMEIDA, W. G. O guia-intérprete e a inclusáo da pessoa com surdocegueira. Tese (Doutorado em Educação) - Universidade Federal da Bahia, Salvador, BA, 2015.

BARROSO, E.; MESQUITA, H. Os desafios da Multideficiência - um olhar sobre uma Unidade de Apoio à Multideficiência. Revista Educaçáo Especial, v. 27, n. 48, p. 219-232, 2014.

BRASIL. Ministério da Educação. Lei Brasileira de Inclusão - Estatuto da pessoa com deficiência, $\mathrm{n}^{\circ} 13.146$ de 06 de julho de 2015. Brasília: MEC, 2015. Disponível em: http://www.planalto.gov.br/ccivil_03/_Ato20152018/2015/Lei/L13146.htm. Acesso: 04. jan. 2017.

Ministério da Educaçấo. Lei no 9394 de Diretrizes e Bases da Educaçấo Nacional. Dez. 1996.

Ministério da Educaçấo. Política de Educação Especial na perspectiva da Educaçáo Inclusiva. Disponível em <http://portal.mec.gov.br/arquivos/pdf/politicaeducespecial.pdf >. Ministério da Educaçáo/ Secretaria de Educação Especial. 2008. Acesso em 21 jan. de 2017.

Ministério da Educação. Estratégias e orientaçóes pedagógicas para a educaçáo de crianças com necessidades educacionais especiais: dificuldades de comunicaçâo e sinalizaçáo: surdez. Educação infantil 7 . Brasília, DF: MEC/SEEP, 2002. Disponível em: < http://portal.mec.gov.br/seb/arquivos/pdf/eduinf_esp_ref.pdf> Acesso em: 02 de fev. 2017.

Ministério da Educação. Resoluçáo no 4, de 2 de outubro de 2009. Institui Diretrizes Operacionais para o Atendimento Educacional Especializado na Educaçáo Básica, modalidade Educaçáo Especial. Secretaria de Educaçāo Especial. Disponível em: < portal.mec.gov.br/dmdocuments/rceb004_09.pdf> Acesso em: 02 de jan.2017.

Ministério da Educaçáo. Resoluçáo no 4, de 13 de julho de 2010. Define Diretrizes Curriculares Nacionais Gerais para a Educação Básica. Secretaria de Educação Especial. Disponível em: < http://portal.mec.gov.br/ dmdocuments/rceb004_10.pdf> Acesso em: 20 de jan. 2017.

Ministério da Educação. $\mathbf{O}$ tradutor e intérprete de língua brasileira de sinais e língua portuguesa. Secretaria de Educação Especial. Brasília: MEC, SEESP, 2004. Disponível em < http://portal.mec.gov.br/seesp/ arquivos/pdf/tradutorlibras.pdf $>$. Acesso em: 03 de jan. 2017.

Ministério da Educação. Resoluçáo no 2, de 11 de setembro de 2001a. Institui Diretrizes Nacionais para Educação Especial na Educação Básica. Secretaria de Educação Especial. Disponível em: < http://portal.mec.gov.br/ cne/arquivos/pdf/CEB0201.pdf> Acesso em: 20 de jan. de 2017.

Diretrizes nacionais para a educaçáo especial na educação básica. Brasília: MEC/CNE/ CEB, 2001 b.

Referencial curricular nacional para a educaçáo infantil. Brasília: MEC/SEF, 1998.

Plano decenal de educaçáo para todos. Brasília: MEC, 1993.

CADER-NASCIMENTO, F. A. A. A. Implementaçáo e avaliaçáo empírica de programas com duas crianças surdocegas, suas família e a professora. Tese (Doutorado em Educação Especial) - Universidade Federal de São Carlos, São Carlos, SP, 2003.

CADER-NASCIMENTO, F. A. A..; COSTA, M. DA P. R. DA. Surdocegueira e a peculiaridade do professor na função de guia-intérprete. In: (Orgs) MENDES, E. G.; ALMEIDA, M. A. A. Das margens o centro: perspectivas para as políticas e práticas educacionais no contexto da educaçáo especial inclusiva. Araraquara, SP: Junqueira\&Marin, 2010.

CADER-NASCIMENTO, F. A. A. A.; COSTA, M. da P. R. da. Descobrindo a surdocegueira - educação e comunicação. São Carlos, SP: Edufscar, 2010.

CAETANO, J.C; LACERDA, C. B. F DE. Libras no currículo de cursos de Licenciatura. In: (Orgs) LACERDA, C. B. F DE.; SANTOS, L. F. DOS. Tenho um aluno surdo, e agora? Introdução à Libras e a educação de surdos. São Carlos: EdUFSCAR, 2014. 
CAMBRUZZI, R. de C. S. Recursos pedagógicos acessíveis ao aluno com surdocegueira por síndrome de Usher: Um estudo de caso. Tese (Doutorado em Educação) - Universidade Federal de São Carlos, São Carlos, SP, 2013.

CAMBRUZZI, R. de C. S.; COSTA, M. da P. R. da. Surdocegueira - níveis e formas de comunicaçấo. São Carlos: Edufscar, 2016.

COSTA, V. A. da. Formação de professores e a sua relação com a educação inclusiva: desafios à experiência teórica na práxis pedagógica. Revista de Educaçáo Especial, v. 28, n. 52, p. 405-416, 2015.

FARIAS, S. S. P. Os processos de inclusão dos alunos com surdocegueira na educaçáo básica. Tese (Doutorado em Educação) - Universidade Federal da Bahia, Salvador, BA, 2015.

GALVÃO, C. M.; SAWADA, N. O.; TREVIZAN, M. A. Revisão sistemática: recurso que proporciona a incorporação das evidências na prática da enfermagem. Revista Latino-Americana de Enfermagem, Ribeirão Preto, v.12, n.3, p. 549-556, 2004.

GALVAO, N. de C. S. S.; MIRANDA, T. G. Atendimento educacional especializado para alunos com surdocegueira: um estudo de caso no espaço da escola regular. Revista Brasileira de Educaçáo Especial, Marília, v. 19, n. 1, p. 43-60, mar. 2013.

GODOY, S. A. Processo de intervençáo junto à professoras especialistas para favorecer a aprendizagem de uma aluna com surdocegueira: Uma pesquisa. Dissertação (Mestrado em Educação) - Universidade Estadual de Londrina, Londrina, PR, 2015.

MASINI, E. F. S. Do sentido, pelos sentidos, para o sentido. Niterói: Intertexto, 2002.

McINNES, J. M. Deaf blindness: a unique disability. In: McINNES, John M. (Org.) A guide to planning and support for individuals who are deafblind. Canada: University of Toronto Press Incorporated, 1999.

McINNES, J. M.; TREFFY, J. A. Deaf-blind infants and children: a developmental guide. Trad. Mary Inês R. M. Loschiavo. São Paulo: AHIMSA, 1991.

MENDES, E. G., FERREIRA, J. R., NUNES, L. R. P. Análise crítica das teses e dissertaçóes sobre Educaçáo Especial nas áreas de Educaçáo e Psicologia - PRODICS IV. Relatório Final de Pesquisa. FAPESP, 2002.

E. G.; VILARONGA, C. A.R.; ZERBATO. A. P., Ensino colaborativo como apoio à inclusáo escolar - unindo esforços entre educação comum e educação especial. São Carlos: EdUFSCAR, 2014.

SANTOS, M. DE J. DOS.; GALVÃO, N. DE C. S.; ARAÚJO, S. C. DE. Deficiência visual e surdocegueira. In: DÍAS, F.; BORDAS, M.; GALVÃO, N.; MIRANDA, T. (Orgs.) Educaçáo inclusiva, deficiência e contexto social: questôes contemporâneas. Salvador: Edufba, 2009. p.255-264. Disponível em: http://www.uff.br/ acessibilidade/files/2009/07/Educacao-Inclusiva.pdf. Acesso em: 19 de set. 2016.

THIOLLENT, M. J. M. Crítica Metodológica, Investigaçáo Social e Enquete Operária. Col. Teoria e História 6. São Paulo: Polis, 1987.

VILLAS-BOAS, D. C. Pessoas com surdocegueira e com deficiência múltipla: Análise de relaçôes e comunicaçóes. Tese (Doutorado em Fonoaudiologia) -Pontifícia Universidade Católica de São Paulo, São Paulo, 2014.

\section{Notas}

${ }^{1}$ Portable Document Format (PDF) é um formato de arquivo usado para exibir e compartilhar documentos de maneira compatível, independentemente de software, hardware ou mesmo do sistema operacional.

${ }^{2}$ Universidade Federal da Bahia.

${ }^{3}$ Universidade Estadual de Londrina.

${ }^{4}$ Pontifícia Universidade Católica de São Paulo.

${ }^{5}$ Universidade Federal de São Carlos.

\section{Correspondência}

Ana Paula Silva Cantarelli Branco - Universidade Federal de São Carlos. Rodovia Washington Luís, s/n. CEP: 13565-905. São Carlos, São Paulo, Brasil. 
Ana Paula Silva Cantarelli Branco - Daniela Leal

E-mail: anapaula.cantarellibranco@gmail.com - dannylegal@gmail.com

Correspondência em 14 de novembro de 2017

Final em 3 de março de 2018 